\title{
$100 \%$ Orange juice consumption is associated with better diet quality, improved nutrient adequacy, decreased risk for obesity, and improved biomarkers of health in adults: National Health and Nutrition Examination Survey, 2003-2006
}

\author{
Carol E O'Neil ${ }^{1 *}$, Theresa A Nicklas², Gail C Rampersaud ${ }^{3}$ and Victor L Fulgoni III ${ }^{4}$
}

\begin{abstract}
Background: Consumption of 100\% orange juice (OJ) has been positively associated with nutrient adequacy and diet quality, with no increased risk of overweight/obesity in children; however, no one has examined these factors in adults. The purpose of this study was to examine the association of 100\% OJ consumption with nutrient adequacy, diet quality, and risk factors for metabolic syndrome (MetS) in a nationally representative sample of adults.

Methods: Data from adults $19+$ years of age $(n=8,861)$ participating in the National Health and Nutrition Examination Survey 2003-2006 were used. The National Cancer Institute method was used to estimate the usual intake (UI) of 100\% OJ consumption, selected nutrients, and food groups. Percentages of the population below the Estimated Average Requirement (EAR) or above the Adequate Intake (AI) were determined. Diet quality was measured by the Healthy Eating Index-2005 (HEl-2005). Covariate adjusted logistic regression was used to determine if consumers had a lower odds ratio of being overweight or obese or having risk factors of MetS or MetS.

Results: Usual per capita intake of 100\% OJ was $50.3 \mathrm{ml} / \mathrm{d}$. Among consumers $(n=2,310 ; 23.8 \%)$, Ul was $210.0 \mathrm{ml} / \mathrm{d}$. Compared to non-consumers, consumers had a higher $(\mathrm{p}<0.05)$ percentage $(\% \pm \mathrm{SE})$ of the population meeting the EAR for vitamin A ( $39.7 \pm 2.5$ vs $54.0 \pm 1.2)$, vitamin C ( $0.0 \pm 0.0$ vs $59.0 \pm 1.4)$, folate $(5.8 \pm 0.7$ vs $15.1 \pm 0.9)$, and magnesium ( $51.6 \pm 1.6$ vs $63.7 \pm 1.2)$. Consumers were also more likely to be above the Al for potassium ( $4.1 \pm 0.8$ vs $1.8 \pm 0.2)$. HEl-2005 was significantly ( $p<0.05$ ) higher in consumers ( $55.0 \pm 0.4 \mathrm{vs} 49.7 \pm 0.3)$. Consumers also had higher intakes of total fruit, fruit juice, whole fruit, and whole grain. Consumers had a lower $(p<0.05)$ mean body mass index ( $27.6 \pm 0.2$ vs $28.5 \pm 0.1$ ), total cholesterol levels (197.6 \pm 1.2 vs $200.8 \pm 0.75 \mathrm{mg} / \mathrm{dL}$ ), and low density lipoprotein-cholesterol levels (112.5 \pm 1.4 vs $116.7 \pm 0.93 \mathrm{mg} / \mathrm{dL})$. Finally, compared to non-consumers of $100 \% \mathrm{OJ}$, consumers were $21 \%$ less likely to be obese and male consumers were $36 \%$ less likely to have MetS.

Conclusion: The results suggest that moderate consumption of 100\% OJ should be encouraged to help individuals meet the USDA daily recommendation for fruit intake and as a component of a healthy diet.
\end{abstract}

Keywords: Orange juice consumption, 100\% fruit juice consumption, Diet quality, Nutrients, Nutrient adequacy, Adults, Weight, Obesity, Metabolic syndrome, NHANES

\footnotetext{
* Correspondence: coneil1@|su.edu

'Louisiana State University Agricultural Center, 261 Knapp Hall, Baton Rouge, Louisiana 70803, USA

Full list of author information is available at the end of the article
} 


\section{Background}

Consumption of $100 \%$ fruit juice (FJ) has been associated with higher intakes of key nutrients, including vitamins $\mathrm{C}$ and B-6, folate, thiamin, magnesium, and potassium, as well as better diet quality, and increased intake of total and whole fruit consumption in children [1-4] and adults [3] as compared to those that do not consume $100 \%$ FJ. There have been concerns about overweight/obesity in consumers of $100 \%$ FJ, especially children [5-7]. Most studies have been conducted in children and have not shown a relationship between $100 \%$ FJ consumption and weight [8]. Cross-sectional studies that have been conducted in adults have shown that consumption of $100 \%$ FJ has been inversely associated with body mass index (BMI) $[9,10]$ and obesity [10]; however, the longitudinal Nurses' Health Study II showed that 100\% FJ consumption was positively associated with weight gain [11].

The relationship between consumption of $100 \% \mathrm{FJ}$ and other markers of disease among adults is inconsistent. Pereira and Fulgoni [10], using data from the National Health and Nutrition Examination Survey (NHANES) 1999-2004 and Yoo et al. [12] using data from the Bogalusa Heart Study, showed no association of risk of metabolic syndrome (MetS) among 100\% FJ consumers; another study showed that, in middle aged and older adults, fasting glucose, but not fasting insulin [13] was lower in $100 \% \mathrm{FJ}$ consumers. In different studies, diabetes risk was shown to be associated with $100 \%$ FJ consumption [14] or not [11]. Data from the CARDIA study have shown an association of a reduced risk of hypertension with $100 \%$ FJ consumption [15]. Since data on the effects of consumption of $100 \%$ OJ on adult health are conflicting, further studies are needed.

Few studies have examined the effect of specific fruit juices on diet and health. Orange juice (OJ) is the most popular 100\% FJ consumed in the US. In 2009, per capita availability of OJ was 14.84 liters [16]. Orange juice is also one of the most nutrient dense $100 \% \mathrm{FJ}$, regardless of type of density measures used in the evaluation [17]. Two hundred and thirty seven $\mathrm{ml}$ of $100 \%$ OJ provides 469 kilojoules $(\mathrm{kJ})$ (112 kcal), $21 \mathrm{~g}$ total sugars, $124 \mathrm{mg}$ vitamin $\mathrm{C}, 27 \mathrm{mg}$ magnesium, $0.10 \mathrm{mg}$ vitamin B-6, $74 \mu \mathrm{g}$ Dietary Folate Equivalents, $496 \mathrm{mg}$ potassium, and only $0.06 \mathrm{~g}$ saturated fatty acids (SFA) and $2.48 \mathrm{mg}$ sodium [18]. Some brands of commercially available $100 \%$ OJ are fortified with fiber, calcium, or vitamin $\mathrm{D}$; these have been identified as nutrients of public health concern in the 2010 Dietary Guidelines for Americans [19].

In vitro [20] and animal studies [21,22] have suggested that citrus juices or components of these juices, including the flavanones hesperidin and naringin (or their aglycone forms hesperetin and naringenin), may have beneficial effects on blood lipids. Clinical studies conducted in adults have shown that consumption of $100 \%$ OJ has been associated with health benefits including positive effects on blood lipids [23-26] - especially in hypercholesterolemic individuals, lower levels of several oxidative or inflammatory stress biomarkers [27-29], and lower blood pressure [30]. Epidemiologic studies, using a nationally representative sample, looking at the association between consumption of $100 \%$ OJ and health markers are lacking. The objective of this study was to examine the association of $100 \%$ OJ usual intakes (UI) on select nutrients, food group equivalents, diet quality, weight parameters, and risk factors associated with cardiovascular disease and metabolic syndrome in adults.

\section{Methods}

\section{Study population}

Data from adults $19+$ yrs $(\mathrm{n}=8,861)$ participating in the NHANES 2003-2006 were combined for these analyses to increase the sample size. Females were excluded from the study if they were pregnant or lactating. Demographic information [31] and physical activity levels [32] were determined from the NHANES interview. NHANES has stringent consent protocols and procedures to ensure confidentiality and protection from identification [33]. Since this was a secondary data analysis with a lack of personal identifiers, this study was exempted by the Louisiana State University Agricultural Center Institutional Review Board.

\section{Determination of dietary intake data}

Dietary data were collected using two 24-hour dietary recalls using an automated multiple-pass method [34,35]; the first recall was conducted in person by a trained interviewer and the second recall was conducted 310 days later via telephone. Only recall data judged to be complete and reliable by the National Center for Health Statistics staff were included in this study. Detailed descriptions of the dietary recalls and data collection are available in the NHANES Dietary Interviewer's Training Manual [36].

In this study, $100 \%$ OJ was defined using the United States Food and Drug Administration definition [37] for $100 \% \mathrm{FJ}$; that is the product contained $100 \% \mathrm{FJ}$-in this case, OJ. This includes 100\% FJ made from concentrate and $100 \%$ FJ with added nutrients, such as calcium or vitamin D; but does not include juice drinks or other products that contain less than 100\% fruit juice. Individual food codes in NHANES 2003-2004 and 2005-2006 were used to determine intake of $100 \%$ OJ. Consumers of $100 \%$ OJ were defined as those participants consuming any amount of $100 \%$ OJ on either day of the 24-hour recalls. To determine nutrient intake, the USDA Food and Nutrient Database for Dietary Studies, versions 2 [38] and 3 [39] were used for NHANES, 2003-2004 and 
2005-2006, respectively. Nutrients examined included macronutrients, dietary fiber, and sodium and also those micronutrients likely to be provided by $100 \%$ OJ: vitamins A, C, and B6; folate; magnesium; and potassium. Intake from supplements was not considered.

\section{Food group equivalent intakes and healthy eating index (HEl-2005)}

Food group equivalent intakes (formerly called MyPyramid equivalents) were determined using MyPyramid Equivalents Database 2.0; when necessary, intakes for NHANES 2005-2006 were hand matched to similar foods. The HEI-2005 was used to determine diet quality [40]. The SAS code used to calculate HEI-2005 scores was downloaded from the Center for Nutrition Policy and Promotion website [41].

\section{Physiological measures}

Height, weight, and waist circumference (WC) were obtained according to NHANES protocols [42]. Body mass index was calculated as body weight (kilograms) divided by height (meters) squared [43]. For the odds ratio (OR) assessments, overweight/obesity and high waist circumference were determined using the National Heart Lung and Blood Institute (NHLBI) Clinical Guidelines [43]. Systolic (SBP) and diastolic blood pressures (DBP) were determined using the standard NHANES protocol [44] and the mean of all values measured was used. Total cholesterol and high density lipoprotein cholesterol (HDL-C) were determined on non-fasted individuals [45] while low density lipoprotein cholesterol (LDL-C) (46), triacylglycerides [46], blood glucose [47], and insulin [47] were determined on only fasted subjects. Per these protocols, not all individuals may have values for all tests (see tables for sample numbers). Metabolic syndrome was defined using the NHLBI Adult Treatment Panel III criteria [48]; that is having 3 or more of the following risk factors: abdominal obesity, WC $>102 \mathrm{~cm}$ (males), $>88 \mathrm{~cm}$ (females); hypertension, $\mathrm{SBP} \geq 130 \mathrm{mmHg}$ or DBP $\geq 85 \mathrm{mmHg}$ or taking anti-hypertensive medications; HDL-C, $<40 \mathrm{mg} / \mathrm{dL}$ (males), $<50 \mathrm{mg} / \mathrm{dL}$ (females); high triacylglycerides, $\geq 150 \mathrm{mg} / \mathrm{dL}$ or taking anti-hyperlipidemic medications; high fasting glucose, $\geq 110 \mathrm{mg} / \mathrm{dL}$ or taking insulin or other hypoglycemic agents.

\section{Statistical analyses}

Sampling weights and the sampling units and strata information, as provided by NHANES, were included in all analyses using SUDAAN v10.0 (Research Triangle Institute; Raleigh, NC). Usual intakes were determined using SAS v 9.2 (SAS Institute, Cary, NC). Usual intake determinations represent long term average daily intakes and are determined by removing excessive intra-person variation in intakes; these are the best estimates to compare to dietary recommendations as suggested intakes are to be met over time, rather than measured on a single day. Usual intake of $100 \%$ OJ consumption and selected nutrients was calculated using the National Cancer Institute (NCI) method [49]. For UI of $100 \%$ OJ, which is consumed episodically, the two part NCI model (probability and amount) was used; for nutrients which are consumed daily by most people, the one part model was used. The NCI SAS macros (Mixtran v1.1 and Distrib v1.1) were used to generate parameter effects after covariate adjustments and to estimate the distribution of usual intake via Monte Carlo simulation methods, respectively [49]. Covariates in this study were day of the week of the 24-hr recall [coded as weekend (Friday-Sunday) or weekday (Monday-Thursday)] and sequence of dietary recall (first or second). Software provided by NCI was used with the two days of intake using one-day sampling weights to obtain appropriate variance estimates. Balanced repeated replication (BRR) was performed to obtain standard errors (SE) and confidence intervals (CI) for the percentiles; BRR weights were constructed with Fay adjustment factor $\mathrm{M}=0.3$ (perturbation factor 0.7 ) and further adjusted to match the initial sample weight totals within specific age/ gender/ethnicity groupings for the full dataset. The Dietary Reference Intake (DRI) age groups were used to present UI for each of the nutrients studied.

To assess the extent of inadequate intake of vitamins A and $\mathrm{C}$, folate, and magnesium, the Estimated Average Requirements (EAR) cut-point method proposed by the Institute of Medicine [50] was used. The EAR is the appropriate DRI to use when assessing the adequacy of group intakes [50]. The EAR cut-point method provides an estimate of the proportion of individuals in the group with inadequate intakes by age and gender. For nutrients without an EAR, i.e. sodium and potassium, the percent above the Adequate Intake (AI) was determined.

To determine if there were significant differences $(\mathrm{p}<0.05)$ for the percentage of $100 \%$ OJ consumers vs non-consumers with intakes less than the EAR or above the AI a Z-statistic for differences in population proportions was used. Linear regression was used to determine differences in $100 \%$ OJ consumers and non-consumers for physiological measures. Logistic regression was used to determine if $100 \%$ OJ consumers had a lower OR of being overweight or obese or had other health risk factors. Covariates for linear and logistic regression included energy (kcals), age, gender, ethnicity, poverty index ratio, and physical activity for body weight and BMI; for other physiological measures BMI was also added as a covariate. Physical activity was determined from physical activity questionnaires and separated subjects into three categories: sedentary, moderate activity, and vigorous activity [51]. 


\section{Results}

Usual intake of orange juice

The sample consisted of adults 19 years of age and older $(\mathrm{n}=8,861)$ of which 2,310 (23.8\%) consumed 100\% OJ. Per capita consumption was $50.3 \pm 1.8 \mathrm{ml} /$ day, whereas among consumers, consumption was $210.0 \pm 3.8 \mathrm{ml} /$ day. Per capita consumption and consumption among consumers was higher in males $(\mathrm{p}<0.05)$ than in females. The $75^{\text {th }}$ percentile among consumers was $259.3 \pm 6.8 \mathrm{ml} /$ day (Table 1).

\section{Usual intake of macronutrients, and selected micronutrients}

The UI of carbohydrates, total sugars, and dietary fiber was higher $(\mathrm{p}<0.05)$ in consumers than in non-consumers (Table 2). Table 3 shows that in $100 \%$ OJ consumers, the $\mathrm{UI}$ of vitamins $\mathrm{A}, \mathrm{B} 6$, and $\mathrm{C}$; folate; and magnesium was higher $(\mathrm{p}<0.05)$ than non-consumers, and consumers were less likely to be below the EAR than non consumers $(\mathrm{p}<0.05)$ (Table 3). Those consuming 100\% OJ had a usual mean intake of vitamin A of $660 \pm 15$ Retinol Activity Equivalents (RAE) $\mu \mathrm{g} / \mathrm{d}$ compared with $580 \pm 8 \mathrm{RAE} \mu \mathrm{g} / \mathrm{d}$; approximately $40 \%$ of those consuming $100 \%$ OJ were below the EAR for vitamin A, compared with $54 \%$ of nonconsumers (both $\mathrm{p}<0.05$ ). Orange juice consumers had a usual mean intake of folate of $606 \pm 10$ Dietary Folate Equivalents (DFE) $\mu \mathrm{g} / \mathrm{d}$ compared with $521 \pm 6$ DFE $\mu \mathrm{g} / \mathrm{d}$; approximately $6 \%$ of $100 \%$ OJ consumers were below the EAR, compared with $15 \%$ for non-consumers (both $\mathrm{p}<0.05$ ). Adults consuming $100 \% \mathrm{OJ}$ had a mean usual intake of vitamin $C$ of $146 \pm 2.4 \mathrm{mg} / \mathrm{d}$ compared with approximately $67 \pm 1.3 \mathrm{mg} / \mathrm{d}$ for non-consumers. On average, $100 \%$ OJ consumers were not below the EAR, compared with $59 \%$ of non-consumers $(\mathrm{p}<0.05)$. Adults that consumed 100\% OJ had higher usual mean intake of $313 \pm$ $4 \mathrm{mg} / \mathrm{d}$ magnesium compared with $283 \pm 3 \mathrm{mg} / \mathrm{d}$ for nonconsumers. Approximately $64 \%$ of adults that consumed $100 \%$ OJ were below the EAR, compared with $52 \%$ for non-consumers (both $\mathrm{p}<0.05$ ). The usual mean intake of potassium of $100 \%$ OJ consumers was $3026 \pm 36 \mathrm{mg} / \mathrm{d}$, compared with $2623 \pm 22 \mathrm{mg} / \mathrm{d}$ for non-consumers;
Table 2 Energy and macronutrient usual intakes among consumers and non-consumers of orange juice

\begin{tabular}{|c|c|c|c|c|c|c|}
\hline \multirow[b]{2}{*}{ Group } & \multirow{2}{*}{$\frac{\text { Usual intake }}{\text { Mean } \pm \text { SE }}$} & \multicolumn{5}{|c|}{ Percentile } \\
\hline & & 10 & 25 & 50 & 75 & 90 \\
\hline \multicolumn{7}{|l|}{ Energy, Kcal/d } \\
\hline Consumer & $2248 \pm 33$ & 1400 & 1702 & 2126 & 2684 & 3569 \\
\hline Non-Consumer & $2185 \pm 15$ & 1339 & 1656 & 2087 & 2622 & 3170 \\
\hline \multicolumn{7}{|l|}{ Protein, g/d } \\
\hline Consumer & $84.9 \pm 1.3$ & 52.2 & 62.5 & 79.8 & 102.0 & 125.3 \\
\hline Non-Consumer & $83.4 \pm 0.7$ & 50.4 & 62.8 & 80.0 & 100.6 & 121.4 \\
\hline \multicolumn{7}{|l|}{ Carbohydrates, g/d } \\
\hline Consumer & $279 \pm 4^{a}$ & 178 & 214 & 265 & 330 & 402 \\
\hline Non-Consumer & $260 \pm 2^{b}$ & 155 & 194 & 248 & 314 & 384 \\
\hline \multicolumn{7}{|l|}{ Total sugars, $\mathrm{g} / \mathrm{d}$} \\
\hline Consumer & $133 \pm 2.3^{\mathrm{a}}$ & 77.4 & 96.9 & 124 & 160 & 201 \\
\hline Non-Consumer & $119 \pm 1.3^{b}$ & 57.2 & 79.0 & 110 & 149 & 192 \\
\hline \multicolumn{7}{|l|}{ Dietary fiber, $\mathrm{g} / \mathrm{d}$} \\
\hline Consumer & $16.6 \pm 0.3^{\mathrm{a}}$ & 9.6 & 12.2 & 15.8 & 20.1 & 24.7 \\
\hline Non-Consumer & $15.3 \pm 0.3^{b}$ & 8.6 & 11.1 & 14.5 & 18.5 & 22.9 \\
\hline \multicolumn{7}{|l|}{ Total fat, $\mathrm{g} / \mathrm{d}$} \\
\hline Consumer & $83.1 \pm 1.4$ & 47.7 & 60.8 & 78.7 & 101.2 & 124.6 \\
\hline Non-Consumer & $83.7 \pm 0.7$ & 47.6 & 61.3 & 79.9 & 102.1 & 125.1 \\
\hline \multicolumn{7}{|c|}{ Saturated fatty acids, g/d } \\
\hline Consumer & $27.4 \pm 0.6$ & 15.2 & 19.6 & 25.8 & 33.4 & 41.6 \\
\hline Non-Consumer & $27.8 \pm 0.3$ & 15.0 & 19.7 & 26.3 & 34.3 & 42.8 \\
\hline
\end{tabular}

Data source: Adults 19+ years of age participating in NHANES 2003-2006 with consumers defined as orange juice consumption on either of two days of intake assessment.

n: 2,310 OJ consumers and 6,551 non-consumers.

Means with different letters are significantly different, $p<0.05$.

approximately $4 \%$ of $100 \%$ OJ consumers were above the AI, compared with only $2 \%$ of non-consumers $(\mathrm{p}<0.05)$.

\section{Diet quality and food group equivalents usual intake}

Diet quality, as measured by HEI-2005, was significantly higher $(\mathrm{p}<0.05)$ in consumers than in non-consumers $(55.0 \pm 0.4$ vs $49.7 \pm 0.3)$ (Table 4). Total fruit $(1.8 \pm 0.05$ vs $0.7 \pm 0.02$ cup equivalents/d), fruit from juice (1.1

Table 1 Usual intake of orange juice $(\mathrm{ml} / \mathrm{d})$ in the total population and consumers

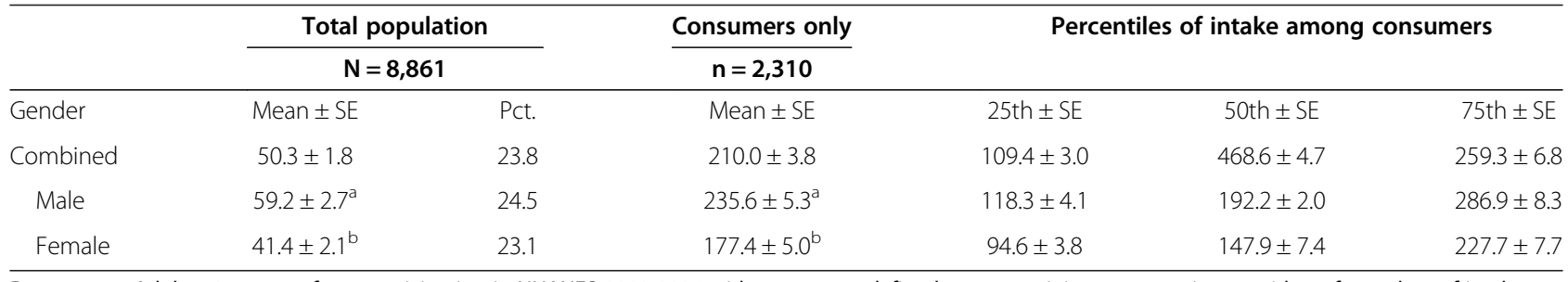

Data source: Adults 19+ years of age participating in NHANES 2003-2006 with consumers defined as orange juice consumption on either of two days of intake assessment.

Means with different letters indicate a significant difference between genders $p<0.05$.

$1 \mathrm{ml}=0.0338$ US fluid oz 
Table 3 Selected micronutrient usual intakes among consumers and non-consumers of orange juice and comparison to Estimated Average Requirements (EAR) or Adequate Intake (AI)

\begin{tabular}{|c|c|c|c|c|c|c|c|}
\hline \multirow[b]{2}{*}{ Group } & \multirow{2}{*}{$\frac{\text { Usual intake }}{\text { Mean } \pm \text { SE }}$} & \multicolumn{5}{|c|}{ Percentile } & \multirow{2}{*}{$\frac{\text { EAR }}{\% \text { Below } \pm \mathrm{SE}}$} \\
\hline & & 10 & 25 & 50 & 75 & 90 & \\
\hline \multicolumn{8}{|l|}{ Vitamin A, RAE ug/d } \\
\hline Consumer & $660 \pm 15^{\mathrm{a}}$ & 364 & 471 & 618 & 802 & 1009 & $39.7 \pm 2.5^{a}$ \\
\hline Non-Consumer & $580 \pm 8^{b}$ & 265 & 373 & 529 & 730 & 960 & $54.0 \pm 1.2^{b}$ \\
\hline \multicolumn{8}{|l|}{ Vitamin B-6, mg/d } \\
\hline Consumer & $2.1 \pm 0.0^{a}$ & 1.3 & 1.6 & 2.0 & 2.6 & 3.2 & $9.5 \pm 1.0^{\mathrm{a}}$ \\
\hline Non-Consumer & $1.9 \pm 0.0^{b}$ & 1.1 & 1.4 & 1.8 & 2.3 & 2.9 & $16.7 \pm 1.4^{b}$ \\
\hline \multicolumn{8}{|l|}{ Folate, DFE ug/d } \\
\hline Consumer & $606 \pm 10^{\mathrm{a}}$ & 358 & 451 & 578 & 730 & 890 & $5.8 \pm 0.7^{\mathrm{a}}$ \\
\hline Non-Consumer & $521 \pm 6^{b}$ & 288 & 371 & 487 & 634 & 796 & $15.1 \pm 0.9^{b}$ \\
\hline \multicolumn{8}{|l|}{ Vitamin C, mg/d } \\
\hline Consumer & $146 \pm 2.4^{\mathrm{a}}$ & 110 & 125 & 148 & 167 & 178 & $0.0 \pm 0.0^{\mathrm{a}}$ \\
\hline Non-Consumer & $66.6 \pm 1.3^{b}$ & 26.1 & 38.9 & 58.5 & 85.4 & 117.1 & $59.0 \pm 1.4^{b}$ \\
\hline \multicolumn{8}{|l|}{ Magnesium, mg/d } \\
\hline Consumer & $313 \pm 4^{a}$ & 193 & 238 & 296 & 372 & 449 & $51.6 \pm 1.6^{a}$ \\
\hline \multirow[t]{2}{*}{ Non-Consumer } & $283 \pm 3^{b}$ & 170 & 213 & 270 & 339 & 411 & $63.7 \pm 1.2^{b}$ \\
\hline & Usual Intake & & & Percentile & & & $\mathrm{Al}$ \\
\hline Group & Mean \pm SE & 10 & 25 & 50 & 75 & 90 & $\%$ Above \pm SE \\
\hline \multicolumn{8}{|l|}{ Sodium, mg/d } \\
\hline Consumer & $3483 \pm 53$ & 2066 & 2604 & 3338 & 4213 & 5107 & $98.4 \pm 0.3$ \\
\hline Non-Consumer & $3501 \pm 29$ & 2137 & 2654 & 3351 & 4194 & 5074 & $98.8 \pm 0.2$ \\
\hline \multicolumn{8}{|l|}{ Potassium, mg/d } \\
\hline Consumer & $3026 \pm 36^{a}$ & 1978 & 2396 & 2939 & 3564 & 4195 & $4.1 \pm 0.8^{a}$ \\
\hline Non-Consumer & $2623 \pm 22^{b}$ & 1610 & 2009 & 2532 & 3140 & 3756 & $1.8 \pm 0.2^{b}$ \\
\hline
\end{tabular}

Data source: Adults 19+ years of age participating in NHANES 2003-2006 with consumers defined as orange juice consumption on either of two days of intake assessment.

$\mathrm{n}: 2,310$ OJ consumers and 6,551 non-consumers.

Means with different letters are significantly different, $\mathrm{p}<0.05$.

\pm 0.03 vs $0.2 \pm 0.01$ cup equivalents/d) and whole fruit $(0.7 \pm 0.03$ vs $0.5 \pm 0.02$ cup equivalents/d) were all higher for consumers as compared to non-consumers. In addition, whole grain consumption was higher $(\mathrm{p}<0.05)$ in consumers ( $0.8 \pm 0.03$ ounce equivalents) than in nonconsumers ( $0.6 \pm 0.02$ ounce equivalents).

\section{Anthropometric and cardiovascular risk factors}

Consumers of $100 \%$ OJ had a lower mean BMI than nonconsumers $\left(27.6 \pm 0.18\right.$ vs $\left.28.5 \pm 0.11 \mathrm{~kg} / \mathrm{m}^{2} ; \mathrm{p}=0.0001\right)$ (Table 5). Adults that consumed $100 \%$ OJ also had lower total cholesterol $(197.6 \pm 1.2 \mathrm{mg} / \mathrm{dL}$ v $200.8 \pm 0.75 \mathrm{mg} / \mathrm{dL}$; $\mathrm{p}=0.0220)$ and lower LDL-C $(112.5 \pm 1.4 \mathrm{mg} / \mathrm{dL}$ v $116.7 \pm$ $0.93 \mathrm{mg} / \mathrm{dL} ; \mathrm{p}=0.0110)$ levels than those that did not consume $100 \%$ OJ. Serum vitamin C $(1.1 \pm 0.01$ vs $0.9 \pm$ $0.01 \mathrm{mg} / \mathrm{dL} ; \mathrm{p}<0.0001)$, red blood cell folate $(309.3 \pm 3.6$ vs $285.3 \pm 2 \mathrm{ng} / \mathrm{ml} \mathrm{RBC;} \mathrm{p}<0.0001)$, and serum folate $(14.8 \pm 0.24$ vs $13.7 \pm 0.25 \mathrm{ng} / \mathrm{ml} ; \mathrm{p}=0.0013)$ were higher in consumers of $100 \%$ OJ than in non-consumers (Table 5).
There were no differences among consumers and nonconsumers in waist circumference, SBP or DBP, C-reactive protein, HDL-cholesterol, triacyglycerides, blood glucose, insulin, or homocysteine levels.

\section{Risk of metabolic syndrome and risk factors for metabolic} syndrome

Males that consumed 100\% OJ showed a 36\% reduced risk [OR: 0.62; $95^{\text {th }}$ CI: 0.45-0.91] of MetS; no differences were observed in females (OR: $1.4195^{\text {th }}$ CI: 0.96-2.07) (Table 6). Male consumers of $100 \%$ OJ also showed a $23 \%$ reduced risk (OR: $0.7795^{\text {th }}$ CI: 0.61-0.99) of low HDL-C levels. Overall there was a $21 \%$ reduced risk (OR: $0.79 ; 95^{\text {th }} \mathrm{CI}$ : $0.65-0.95$ ) of obesity in adults that consumed $100 \%$ OJ compared with non-consumers.

\section{Discussion}

Approximately $24 \%$ of the population consumed 100\% OJ on either of the days when a 24 hour recall was taken. 


\begin{abstract}
Table 4 Diet quality, as measured by healthy eating index and select usual intakes of MyPyramid food components among consumers and non-consumers of orange juice
\end{abstract}

\begin{tabular}{llllllll}
\hline & Usual intake & & \multicolumn{5}{c}{ Percentile } \\
\cline { 2 - 5 } \cline { 5 - 8 } Group & Mean \pm SE & & 10 & 25 & 50 & 75 & 90 \\
\hline
\end{tabular}

Healthy Eating Index, score

$\begin{array}{lllllll}\text { Consumer } & 55.0 \pm 0.4^{\mathrm{a}} & 44.5 & 49.3 & 54.9 & 60.6 & 65.7 \\ \text { Non-Consumer } & 49.7 \pm 0.3^{\mathrm{b}} & 38.4 & 43.5 & 49.4 & 55.6 & 61.4\end{array}$

Total dairy, cup equivalents

$\begin{array}{lcccccc}\text { Consumer } & 1.6 \pm 0.05 & 0.6 & 0.9 & 1.4 & 2.1 & 2.9 \\ \text { Non-Consumer } & 1.5 \pm 0.002 & 0.5 & 0.8 & 1.3 & 2.0 & 2.8\end{array}$

Total fruit, cup equivalents

$\begin{array}{lllllll}\text { Consumer } & 1.8 \pm 0.05^{\mathrm{a}} & 1.1 & 1.4 & 1.8 & 2.1 & 2.3 \\ \text { Non-Consumer } & 0.7 \pm 0.02^{\mathrm{b}} & 0.2 & 0.3 & 0.6 & 0.9 & 1.4\end{array}$

Fruit juice, cup equivalents

$\begin{array}{lllllcl}\text { Consumer } & 1.1 \pm 0.03^{\mathrm{a}} & 0.8 & 0.9 & 1.1 & 1.3 & 1.4 \\ \text { Non-Consumer } & 0.2 \pm 0.01^{\mathrm{b}} & 0.0 & 0.0 & 0.1 & 0.20 .4 & \end{array}$

Whole fruit, cup equivalents

$\begin{array}{lllllll}\text { Consumer } & 0.7 \pm 0.03^{\mathrm{a}} & 0.1 & 0.3 & 0.6 & 1.0 & 1.4 \\ \text { Non-Consumer } & 0.5 \pm 0.02^{\mathrm{b}} & 0.1 & 0.2 & 0.4 & 0.7 & 1.1\end{array}$

Total grain, ounce equivalents

$\begin{array}{lllllll}\text { Consumer } & 7.0 \pm 0.1 & 4.2 & 5.3 & 6.7 & 8.4 & 10.0 \\ \text { Non-Consumer } & 6.8 \pm 0.1 & 3.8 & 4.9 & 6.4 & 8.3 & 10.3\end{array}$

Whole grain, ounce equivalents

$\begin{array}{lllllll}\text { Consumer } & 0.8 \pm 0.03^{\mathrm{a}} & 0.2 & 0.4 & 0.7 & 1.0 & 1.5 \\ \text { Non-Consumer } & 0.6 \pm 0.02^{\mathrm{b}} & 0.1 & 0.2 & 0.5 & 0.9 & 1.3\end{array}$

Total vegetables, cup equivalents

$\begin{array}{lllllll}\text { Consumer } & 1.7 \pm 0.03 & 0.9 & 1.2 & 1.6 & 2.0 & 2.5\end{array}$

$\begin{array}{lllllll}\text { Non-Consumer } & 1.6 \pm 0.03 & 0.9 & 1.2 & 1.5 & 2.0 & 2.5\end{array}$

Data source: Adults 19 + years of age participating in NHANES 2003-2006 with consumers defined as orange juice consumption on either of two days of intake assessment.

n: 2,310 OJ consumers and 6,551 non-consumers.

Means with different letters are significantly different, $p<0.05$.

Males consumed more $100 \%$ OJ, both as a percentage of consumers and in amount. The percent of consumers was similar to that of children [52]. Per capita UI consumption was $50.3 \mathrm{ml} / \mathrm{d}$; however the UI for consumers was $210.0 \mathrm{ml} / \mathrm{d}$. Unlike children, where there is a specific recommendation for consumption of $100 \% \mathrm{FJ}$ [53], there is no recommendation for consumption of $100 \% \mathrm{FJ}$ by adults, other than "the majority of the fruit recommended should come from whole fruits, including fresh, canned, frozen, and dried forms, rather than from juice" [19].

The rationale for limiting $100 \% \mathrm{FJ}$ intake is that it lacks fiber and can contribute to excess energy consumption when consumed in excess [19]. A modeling study, commissioned by the 2005 Dietary Guidelines Advisory
Committee [54] suggested that dietary fiber was lower when whole fruit was removed from the diet, which led to the recommendation that intake of no more than onethird of fruit servings should come from 100\% FJ and twothirds should come from whole fruit. However, this study and others [1-4,52] have shown that either consumers of $100 \%$ FJ had higher intakes of dietary fiber than nonconsumers or there was no difference in fiber consumption between the groups. Since 100\% FJ is low in dietary fiber, it suggests that other higher fiber foods, including whole fruit, are consumed by consumers of $100 \%$ FJ; this was shown not only in this study of $100 \%$ OJ consumers, but has been shown in other studies as well $[1,2,52]$.

As expected, $100 \%$ OJ consumers had increased intake of nutrients typically found in $100 \%$ OJ (i.e. vitamin C, folate, and potassium). Consumers were also less likely to have intakes below the EAR for vitamins A, B-6, and $\mathrm{C}$; folate; and magnesium than non-consumers. The reduction in the percentage of the population with inadequate intakes of these nutrients associated with 100\% OJ consumption indicates the value of consuming a nutrient dense beverage [17]. Mean potassium UI was also higher in consumers than non-consumers and the percentage of the population above the AI was higher. This is an important finding since potassium was identified as a nutrient of public health concern [19]. To our knowledge this is the first report studying the association between the consumption of $100 \% \mathrm{OJ}$ and nutrient adequacy in adults using the recommended UI procedures.

Diet quality, as measured by HEI-2005, was approximately $10 \%$ higher in $100 \%$ OJ consumers. While the increase was due in part to the increase in whole fruit and FJ consumption, consumers also had a higher UI of whole grains. Although intake of total fruit, whole fruit, and FJ was higher in $100 \%$ OJ consumers, overall intake from the fruit food groups was low. Despite extensive, coordinated public health campaigns by government, industry, and others [55], fruit consumption in adults remains low [56]. Since a $236.6 \mathrm{ml}$ serving of $100 \%$ OJ counts as part of the recommendation for the fruit group, moderate consumption of $100 \%$ OJ can help individuals meet fruit intake recommendations.

The potential association of consumption of $100 \% \mathrm{FJ}$ and weight in children has been debated in the literature for more than a decade [1,2,5-8,57-62]; however, less is known about this relationship in adults. Participants in the Nurses' Health Study II with a higher consumption of $100 \%$ FJ had a larger weight gain than those with lower fruit 100\% FJ consumption, although the amounts and types of $100 \%$ FJ consumed, and specific covariates used in the analyses, were not clear [11]. Another study [9] showed that self reported BMI was lower in consumers of $100 \%$ FJ. Ours was the first study that used a nationally representative adult population that showed consumers of 
Table 5 Physiological measures among consumers and non-consumers of orange juice

\begin{tabular}{|c|c|c|c|c|c|}
\hline \multirow[b]{2}{*}{ Variable } & \multicolumn{2}{|c|}{ Consumers } & \multicolumn{2}{|c|}{ Non-consumers } & \multirow[b]{2}{*}{ p-Value } \\
\hline & n & $\mathrm{LSM} \pm \mathrm{SE}$ & $\mathbf{n}$ & $\mathrm{LSM} \pm \mathrm{SE}$ & \\
\hline Body Weight ${ }^{*}(\mathrm{~kg})$ & 2130 & $81.3 \pm 0.20$ & 6150 & $81.4 \pm 0.12$ & 0.5072 \\
\hline $\operatorname{BMI}^{*}\left(\mathrm{~kg} / \mathrm{m}^{2}\right)$ & 2130 & $27.6 \pm 0.18$ & 6150 & $28.5 \pm 0.11$ & $<0.0001$ \\
\hline Waist Circumference ${ }^{*}(\mathrm{~cm})$ & 2069 & $97.1 \pm 0.17$ & 6005 & $97.3 \pm 0.10$ & 0.4381 \\
\hline Systolic Blood Pressure $(\mathrm{mmHg})^{* *}$ & 1801 & $124.0 \pm 0.53$ & 5296 & $123.8 \pm 0.30$ & 0.7604 \\
\hline Diastolic Blood Pressure $(\mathrm{mmHg})^{* *}$ & 1801 & $70.8 \pm 0.42$ & 5296 & $71.3 \pm 0.23$ & 0.2976 \\
\hline Serum Vitamin $C(\mathrm{mg} / \mathrm{dL})^{* *}$ & 2022 & $1.1 \pm 0.01$ & 5813 & $0.91 \pm 0.01$ & $<0.0001$ \\
\hline C-Reactive Protein $^{* *}(\mathrm{mg} / \mathrm{dL})$ & 2041 & $0.43 \pm 0.03$ & 5874 & $0.41 \pm 0.01$ & 0.5922 \\
\hline Total Cholesterol ${ }^{* *}(\mathrm{mg} / \mathrm{dL})$ & 2034 & $197.6 \pm 1.2$ & 5857 & $200.8 \pm 0.75$ & 0.0220 \\
\hline HDL-Cholesterol ${ }^{* *}(\mathrm{mg} / \mathrm{dL})$ & 2033 & $53.7 \pm 0.45$ & 5857 & $53.8 \pm 0.24$ & 0.8230 \\
\hline Triglycerides $^{* *}$ (mg/dL) & 954 & $141.6 \pm 3.6$ & 2833 & $147.4 \pm 3.3$ & 0.2246 \\
\hline LDL-Cholesterol $^{* *}(\mathrm{mg} / \mathrm{dL})$ & 939 & $112.5 \pm 1.4$ & 2746 & $116.7 \pm 0.93$ & 0.0110 \\
\hline Plasma Glucose ${ }^{* *}(\mathrm{mg} / \mathrm{dL})$ & 960 & $103.0 \pm 1.4$ & 2856 & $102.4 \pm 0.62$ & 0.6853 \\
\hline Insulin ${ }^{* *}(\mathrm{u} / \mathrm{mL})$ & 951 & $11.6 \pm 0.38$ & 2823 & $11.3 \pm 0.25$ & 0.4441 \\
\hline RBC Folate $^{* *}(\mathrm{ng} / \mathrm{mL} \mathrm{RBC})$ & 2044 & $309.3 \pm 3.6$ & 5872 & $285.3 \pm 2.0$ & $<0.0001$ \\
\hline Serum Folate $(\mathrm{ng} / \mathrm{mL})$ & 2037 & $14.8 \pm 0.24$ & 5849 & $13.7 \pm 0.25$ & 0.0013 \\
\hline Homocysteine $^{* *}$ (umol/L) & 1988 & $8.7 \pm 0.08$ & 5729 & $8.9 \pm 0.06$ & 0.0853 \\
\hline
\end{tabular}

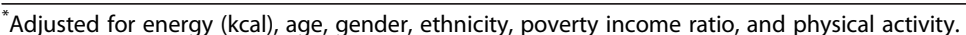

${ }^{* *}$ Adjusted for energy (kcal), age, gender, ethnicity, poverty income ratio, BMI, and physical activity.

Abbreviations: $L S M=$ least square mean; $S E=$ standard error; $B M I=$ body mass index; HDL-C = high density lipoprotein-cholesterol; LDL-C = low-density lipoproteincholesterol; $\mathrm{RBC}=$ red blood cell.

Table 6 Risk of metabolic syndrome, increased risk of individual metabolic syndrome components and other health factors among adult (19+ yrs) consumers and non-consumers of orange juice

\begin{tabular}{|c|c|c|c|c|c|c|c|c|c|}
\hline \multirow[t]{2}{*}{ Risk } & $\mathrm{OR} \pm \mathrm{SE}$ & $\mathrm{LCL}, \mathrm{UCL}$ & p-Value & $\mathrm{OR} \pm \mathrm{SE}$ & $\mathrm{LCL}, \mathrm{UCL}$ & p-Value & $\mathrm{OR} \pm \mathrm{SE}$ & $\mathrm{LCL}, \mathrm{UCL}$ & p-Value \\
\hline & \multicolumn{3}{|c|}{ All } & \multicolumn{3}{|c|}{ Female } & \multicolumn{3}{|c|}{ Male } \\
\hline MetS & $0.93 \pm 0.13$ & $0.71,1.22$ & 0.5790 & $1.41 \pm 0.28$ & $0.96,2.07$ & 0.0795 & $0.64 \pm 0.12$ & $0.45,0.91$ & 0.0119 \\
\hline Elevated BP & $0.98 \pm 0.07$ & $0.85,1.13$ & 0.7586 & $0.98 \pm 0.15$ & $0.73,1.31$ & 0.8948 & $0.95 \pm 0.12$ & $0.75,1.22$ & 0.7078 \\
\hline High Glucose & $0.96 \pm 0.10$ & $0.78,1.18$ & 0.6772 & $1.08 \pm 0.17$ & $0.79,1.47$ & 0.6180 & $0.82 \pm 0.11$ & $0.64,1.06$ & 0.1361 \\
\hline High TG & $1.11 \pm 0.13$ & $0.89,1.39$ & 0.3575 & $1.41 \pm 0.25$ & $1.00,1.99$ & 0.0503 & $0.91 \pm 0.11$ & $0.72,1.15$ & 0.4474 \\
\hline Elevated WC & $0.98 \pm 0.15$ & $0.73,1.33$ & 0.9067 & $1.09 \pm 0.24$ & $0.72,1.66$ & 0.6890 & $0.83 \pm 0.15$ & $0.59,1.18$ & 0.3052 \\
\hline Low HDL-C & $0.92 \pm 0.08$ & $0.78,1.09$ & 0.3518 & $1.08 \pm 0.11$ & 0.891 .31 & 0.4271 & $0.77 \pm 0.10$ & $0.61,0.99$ & 0.0406 \\
\hline Obese & $0.79 \pm 0.08$ & $0.65,0.95$ & 0.0116 & $0.76 \pm 0.10$ & $0.59,0.97$ & 0.0289 & $0.79 \pm 0.09$ & $0.64,0.97$ & 0.0276 \\
\hline Overweight & $1.13 \pm 0.07$ & $0.99,1.28$ & 0.0699 & $1.18 \pm 0.10$ & $0.99,1.39$ & 0.0581 & $1.07 \pm 0.09$ & $0.91,1.26$ & 0.3976 \\
\hline Overweight or Obese & $0.89 \pm 0.07$ & $0.76,1.04$ & 0.1437 & $0.88 \pm 0.09$ & $0.73,1.08$ & 0.2216 & $0.85 \pm 0.09$ & $0.69,1.06$ & 0.1461 \\
\hline High LDL-C & $0.82 \pm 0.10$ & $0.66,1.03$ & 0.0908 & $0.76 \pm 0.12$ & $0.57,1.03$ & 0.0783 & $0.85 \pm 0.14$ & $0.63,1.16$ & 0.3163 \\
\hline
\end{tabular}

* Reference group: Non-consumers of orange juice with odds ratio set at 1.0.

All Metabolic Syndrome Components: Elevated Waist Circumference $\geq 102 \mathrm{~cm}$ in men or $\geq 88 \mathrm{~cm}$ in women; Elevated Triglycerides $\geq 150 \mathrm{mg} / \mathrm{dL}$ or taking medication for Elevated Triglycerides (Antihyperlipidemic Agents or Nicotinic Acid Derivatives); Reduced HDL-C $<40 \mathrm{mg} / \mathrm{dL}$ in men or $<50 \mathrm{mg} / \mathrm{dL}$ in women or taking medication for Reduced HDL-C (Antihyperlipidemic Agents or Nicotinic Acid Derivatives); Elevated BP $\geq 130 \mathrm{mmHg}$ Systolic or $\geq 85 \mathrm{mmHg}$ Diastolic or taking medication for Elevated BP (Antihypertensive Combinations); Elevated Fasting Glucose $\geq 100 \mathrm{mg} / \mathrm{dL}$ or taking medication for Elevated Glucose (Antidiabetic Agents); Metabolic Syndrome ( $\geq 3$ risk factors above). Other risk factors: Elevated LDL-C $\geq 100 \mathrm{mg} / \mathrm{dL}$; Overweight BMI $\geq 25$ and $<30$; Obese BMI $\geq 30$; Overweight or Obese $\mathrm{BMI} \geq 25$.

Abbreviations: $\mathrm{OR}=$ odds Ratio; $\mathrm{LCL}=$ lower confidence level; $\mathrm{UCL}=$ upper confidence level; $\mathrm{SE}=$ standard error; MetS = metabolic syndrome; $\mathrm{BP}=$ blood pressure; TG = triglycerides; $\mathrm{WC}=$ waist circumference; $\mathrm{HDL}-\mathrm{C}=$ high density lipoprotein-cholesterol; $\mathrm{LDL}-\mathrm{C}=$ low density lipoprotein-cholesterol. 
100\% OJ had a lower BMI than non-consumers. These findings are important since $100 \%$ OJ has the highest per capita consumption [16] among the juices and therefore has the potential to be an important component of the diet. Clinical studies that incorporated high levels of $100 \%$ OJ (750 $\mathrm{ml} \mathrm{[24]} \mathrm{or} 500 \mathrm{ml}$ [30]) as an intervention have reported no increases in weight or other anthropometric measures over the course of the study.

Total cholesterol levels and LDL-C levels were both significantly lower in consumers of $100 \%$ OJ than nonconsumers. Compounds found in 100\% OJ, including hesperidin, naringin, or limonoids or their circulating aglycone forms, have been shown to lower total or LDL$\mathrm{C}$ in animal models $[63,64]$. It was hypothesized that these compounds may have inhibited 3-Hydroxy-3-methylglutaryl coenzyme A reductase and increased the expression of LDL-C receptors in the liver, a mechanism similar to statins. These compounds have also been shown to reduce the net secretion of apolipoprotein $B$, which in turn may help inhibit cholesterol ester synthesis $[20,65]$.

Orange juice, at higher intake amounts $(750 \mathrm{ml})$ has also been shown to lower LDL-C and raise HDL-C in a randomized clinical trial of hypercholesterolemia individuals [24]. Although the present study did not look separately at individuals with hypercholesterolemia, it did show that a more realistic consumption of $100 \%$ OJ was associated with reduced total cholesterol and LDL-C levels. It is not clear why there was no difference shown between HDL-C levels between 100\% OJ consumers and non-consumers, as may have been suggested by clinical trials; the response may be dose-dependent or dependent on continual consumption. There was a $23 \%$ lower risk of low HDL-C levels in males only.

Consumption of $100 \%$ OJ was associated with a $21 \%$ lower risk of obesity in men and women. This was similar to the findings of Pereira and Fulgoni [10] that looked at the risk of obesity and consumption of $100 \%$ FJ in participants of NHANES 1999-2004. They also showed a significantly lower risk of metabolic syndrome, whereas this study showed a lower risk in males only. That study showed a much higher intake of $100 \% \mathrm{FJ}$, compared with the intake of $100 \%$ OJ only; but there were also other differences in the population, since they showed, for example that consumers were more likely to be female. Our study showed that $100 \%$ OJ consumers were more likely to be males. Consumption differences of $100 \% \mathrm{FJ}$ in adults need to be studied further.

Strengths of this study include that it encompassed a large nationally representative sample achieved through combining several sets of NHANES data releases. The study also uses the NCI method to assess UI and the percentage of the population below recommended levels in $100 \%$ OJ consumers and non-consumers, as well as adjustment for numerous covariates including physical activity.
Twenty-four hour dietary recalls have several inherent limitations. Participants relied on memory to self-report dietary intakes; therefore, data were subject to nonsampling errors, including underreporting of energy and examiner effects. Respondents may not have differentiated between $100 \%$ OJ or a fruit drink/ade. Confusion over these beverages has been reflected in several studies that assessed a combined $100 \% \mathrm{FJ}$ and juice drink or sweetened FJ category [66-69]. The use of AI cannot be used to determine the prevalence of inadequate intake in a group. Rather, if the mean intake of a group is at or above the AI, and the variance of intake in the group of interest is similar to the variance of intake used in the population originally used to set the AI, the prevalence of inadequate nutrient intakes is likely to be low [50]. Finally, since causal inferences cannot be drawn from NHANES analyses, and due to multi-collinearity of diet, foods other than $100 \%$ OJ may have contributed to differences in nutrient intake of the participants.

\section{Conclusions}

Consumption of $100 \%$ OJ was associated with better diet quality and an increased prevalence of meeting the EAR for key nutrients and other biomarkers of positive health outcomes, including lower total cholesterol and LDL levels. Consumers of $100 \%$ OJ had lower mean BMI and a decreased risk of obesity. In addition, males had a decreased risk of metabolic syndrome. These results suggested that $100 \%$ OJ consumption should be encouraged as a component of a healthy diet to help individuals meet nutrient and fruit intake recommendations.

\section{Abbreviations}

Al: Adequate intake; BMI: Body mass index; BRR: Balanced repeated replication; Cl: Confidence interval; DBP: Diastolic blood pressure;

DFE: Dietary folate equivalents; DRI: Dietary reference intake; EAR: Estimated average requirements; FJ: 100\% Fruit juice; HDL-C: High density lipoproteincholesterol; HEl-2005: Healthy eating index-2005; LDL-C: Low density lipoprotein-cholesterol; MetS: Metabolic syndrome; NHANES: National health and Nutrition examination survey; NHLBI: National heart, lung, and blood institute; OJ: 100\% Orange juice; OR: Odds ratio; RAE: Retinol activity equivalents; SBP: Systolic blood pressure; SFA: Saturated fatty acids; UI: Usual intake; WC: Waist circumference.

\section{Competing interests}

Gail Rampersaud's position at the University of Florida is co-funded by the Florida Department of Citrus. None of the other authors declare a competing interest.

\section{Authors' contributions}

All authors contributed equally to this work. All authors read and approved the final manuscript.

\section{Acknowledgements}

This work is a publication of the United States Department of Agriculture (USDA/ARS) Children's Nutrition Research Center, Department of Pediatrics, Baylor College of Medicine, Houston, Texas. The contents of this publication do not necessarily reflect the views or policies of the USDA, nor does mention of trade names, commercial products, or organizations imply endorsement from the U.S. government. This research project was supported by the Florida Department of Citrus, and USDA - Agricultural Research 
Service through specific cooperative agreement 58-6250-6-003. Partial support was received from the USDA Hatch Project LAB 93951.

\section{Author details}

'Louisiana State University Agricultural Center, 261 Knapp Hall, Baton Rouge, Louisiana 70803, USA. ${ }^{2}$ USDA/ARS Children's Nutrition Research Center, Department of Pediatrics, Baylor College of Medicine, Houston, Texas 77030, USA. ${ }^{3}$ Food Science and Human Nutrition Department, University of Florida, Gainesville, Florida 32611, USA. ${ }^{4}$ Nutrition Impact, LLC, Battle Creek, Michigan 49014, USA.

Received: 9 March 2012 Accepted: 30 November 2012

Published: 12 December 2012

\section{References}

1. Nicklas TA, O'Neil CE, Kleinman R: Association between $100 \%$ juice consumption and nutrient intake and weight in children aged 2 to 11 years. Arch Ped Adolesc Med 2008, 162:557-565.

2. O'Neil CE, Nicklas TA, Kleinman R: Relationship between $100 \%$ juice consumption and nutrient intake and weight of adolescents. Am J Health Promot 2010, 24:231-237.

3. O'Neil CE, Nicklas TA, Zanovec M, Fulgoni VL 3rd: Diet quality is positively associated with $100 \%$ fruit juice consumption in children and adults in the United States: NHANES 2003-2006. Nutr J 2011, 10:17.

4. O'Neil CE, Nicklas TA, Zanovec M, Kleinman RE, Fulgoni VL: Fruit juice consumption is associated with improved nutrient adequacy in children and adolescents: the National Health and Nutrition Examination Survey (NHANES) 2003-2006. Public Health Nutr 2012, 15:1871-1978.

5. Dennison BA, Rockwell HL, Baker SL: Excess fruit juice consumption by preschool-aged children is associated with short stature and obesity. Pediatrics 1997, 99:15-22.

6. Dennison BA, Rockwell HL, Nichols MJ, Jenkins P: Children's growth parameters vary by type of fruit juice consumed. Am Coll Nutr 1999, 18:346-352.

7. Faith MS, Dennison BA, Edmunds LS, Stratton HH: Fruit juice intake predicts increased adiposity gain in children from low-income families: weight status-by environment interaction. Pediatrics 2006, 118:2066-2075.

8. O'Neil CE, Nicklas TA: A review of the relationship between $100 \%$ fruit juice consumption and weight in children and adolescents. Am J Lifestyle Med 2008, 2:315-354.

9. Akhtar-Danesh N, Dehghan M: Association between fruit juice consumption and self-reported body mass index among adult Canadians. J Hum Nutr Diet 2010, 23:162-168.

10. Pereira MA, Fulgoni VL 3rd: Consumption of $100 \%$ fruit juice and risk of obesity and metabolic syndrome: findings from the national health and nutrition examination survey 1999-2004. J Am Coll Nutr 2010, 29:625-629.

11. Schulze MB, Manson JE, Ludwig DS, Colditz GA, Stampfer MJ, Willett WC, Hu FB: Sugar-sweetened beverages, weight gain, and incidence of type 2 diabetes in young and middle-aged women. JAMA 2004, 292:927-934.

12. Yoo S, Nicklas T, Baranowski T, Zakeri IF, Yang SJ, Srinivasan SR, Berenson GS: Comparison of dietary intakes associated with metabolic syndrome risk factors in young adults: the Bogalusa heart study. Am J Clin Nutr 2004, 80:841-848

13. Yoshida M, McKeown NM, Rogers G, Meigs JB, Saltzman E, D'Agostino R, Jacques PF: Surrogate markers of insulin resistance are associated with consumption of sugar-sweetened drinks and fruit juice in middle and older-aged adults. J Nutr 2007, 137:2121-2127.

14. Bazzano LA, Li TY, Joshipura KJ, Hu FB: Intake of fruit, vegetables, and fruit juices and risk of diabetes in women. Diabetes Care 2008, 31:1311-1317.

15. Duffey KJ, Gordon-Larsen P, Steffen LM, Jacobs DR Jr, Popkin BM: Drinking caloric beverages increases the risk of adverse cardiometabolic outcomes in the Coronary Artery Risk Development in Young Adults (CARDIA) Study. Am J Clin Nutr 2010, 92:954-959.

16. United States Department of Agriculture. Economic Research Service: Food availability spread sheets. http://www.ers.usda.gov/data/foodconsumption/ FoodAvailspreadsheets.htm\#fruitju. Accessed January 23, 2012.

17. Rampersaud GC: A comparison of nutrient density scores for $100 \%$ fruit juices. J Food Sci 2007, 72:S261-S266.

18. United States department of agriculture nutrient database. NDB No: 09206. http://www.nal.usda.gov/fnic/cgi-bin/list_nut.pl. Accessed January 24, 2012.
19. United States Department of Agriculture and U.S. Department of Health and Human Services: Dietary guidelines for Americans, 2010. 7th edition. Washington, DC: U.S: Government Printing Office; 2010. http://www.cnpp. usda.gov/DGAs2010-PolicyDocument.htm. Accessed June 21, 2011.

20. Borradaile NM, Carroll KK, Kurowska EM: Regulation of HepG2 cell apolipoprotein B metabolism by the citrus flavanones hesperetin and naringenin. Lipids 1999, 34:591-598.

21. Daher CF, Abou-Khalil J, Baroody GM: Effect of acute and chronic grapefruit, orange, and pineapple juice intake on blood lipid profile in normolipidemic rat. Med Sci Monit 2005, 11:BR465-472.

22. Gorinstein S, Leontowicz H, Leontowicz M, Krzeminski R, Gralak M, MartinBelloso O, Delgado-Licon E, Haruenkit R, Katrich E, Park YS, Jung ST, Trakhtenberg S: Fresh Israeli Jaffa blond (Shamouti) orange and Israeli Jaffa red Star Ruby (Sunrise) grapefruit juices affect plasma lipid metabolism and antioxidant capacity in rats fed added cholesterol. J Agric Food Chem 2004, 52:4853-4859.

23. Kurowska EM, Spence JD, Jordan J, Wetmore S, Freeman DJ, Piché LA, et al: $\mathrm{HDL}$-cholesterol-raising effect of orange juice in subjects with hypercholesterolemia. Am J Clin Nutr 2000, 72:1095-1100.

24. Cesar TB, Aptekmann NP, Araujo MP, Vinagre CC, Maranhao RC: Orange juice decreases low-density lipoprotein cholesterol in hypercholesterolemic subjects and improves lipid transfer to highdensity lipoprotein in normal and hypercholesterolemic subjects. Nutr Res 2010, 30:689-694.

25. Aptekmann NP, Cesar TB: Orange juice improved lipid profile and blood lactate of overweight middle-aged women subjected to aerobic training. Maturitas 2010, 67:343-347.

26. Roza JM, Xian-Liu Z, Guthrie N: Effect of citrus flavonoids and tocotrienols on serum cholesterol levels in hypercholesterolemic subjects. Altern Ther Health Med 2007, 13:44-48.

27. Ghanim H, Sia CL, Upadhyay M, Korzeniewski K, Viswanathan P, Abuaysheh S, et al: Orange juice neutralizes the pro-inflammatory effect of a high-fat, high-carbohydrate meal and prevents endotoxin increase and Toll-like receptor expression. Am J ClinNutr 2010, 91:940-949.

28. Sanchez-Moreno C, Cano MP, de Ancos B, Plaza L, Olmedilla B, Granado F, Martin $A$ : Effect of orange juice intake on vitamin $C$ concentrations and biomarkers of antioxidant status in humans. Am J Clin Nutr 2003, 78:454-460.

29. Sanchez-Moreno C, Canob MP, de Ancosb B, Plazab L, Olmedillac B, Granadoc F, Elez-Martinez P, Martin-Bellosod M, Martina A: Pulsed electric fields-processed orange juice consumption increases plasma vitamin $C$ and decreases F2-isoprostanes in healthy humans. Nutr Biochem 2004, 15:601-607.

30. Morand C, Dubray C, Milenkovic D, Lioger D, Martin JF, Scalbert A, et al: Hesperidin contributes to the vascular protective effects of orange juice: a randomized crossover study in healthy volunteers. Am J Clin Nutr 2011, 93:73-80.

31. National Health and Nutrition Examination Survey: 2003-2004 Data Documentation, Codebook, and Frequencies. Demographic Variables and Sample Weights (DEMO_C). Last revised, September, 2009. [http://www.cdc. gov/nchs/nhanes/nhanes2003-2004/DEMO_C.htm.] Accessed June 21, 2011.

32. National Health and Nutrition Examination Survey: 2003-2004 Data documentation, codebook, and frequencies. L physical activity monitor (PAXRAW_C). Last revised, December, 2007. [http://www.cdc.gov/nchs/ nhanes/nhanes2003-2004/PAXRAW_C.htm.] Accessed June 21, 2011.

33. NHANES: Is my survey information confidential? December, 2007; http://www. cdc.gov/nhanes/pQuestions.htm\#. Accessed December 18, 2009.

34. Moshfegh AJ, Rhodes DG, Baer DJ, Murayi T, Clemens JC, Rumpler W, et al: The US department of agriculture automated multiple-pass method reduces bias in the collection of energy intakes. Am J Clin Nutr 2008, 88:324-332.

35. Blanton CA, Moshfegh AJ, Baer DJ, Kretsch MJ: The USDA automated multiple-pass method accurately estimates group total energy and nutrient intake. J Nutr 2006, 136:2594-2599.

36. National Center for Health Statistics: The NHANES 2002 MEC in-person dietary interviewers procedures manual. http://www.cdc.gov/nchs/data/nhanes/ nhanes_01_02/dietary_year_3.pdf. Accessed June 21, 2011.

37. US Food and Drug Administration: 4. Name of food. Guidance for industry: a food labeling guide. http://www.fda.gov/Food/ GuidanceComplianceRegulatoryInformation/GuidanceDocuments/ FoodLabelingNutrition/FoodLabelingGuide/ucm064872.htm. Accessed January 20, 2011 
38. U.S. Department of Agriculture, Agricultural Research Service: The USDA food and nutrient database for dietary studies, 2.0-Documentation and user guide, 2006. http://www.ars.usda.gov/SP2UserFiles/Place/12355000/pdf/fndds2_doc pdf\#title. Accessed June 21, 2011.

39. U.S. Department of Agriculture, Agricultural Research Service: The USDA food and nutrient database for dietary studies, 3.0-Documentation and user guide; 2008. http://www.ars.usda.gov/SP2UserFiles/Place/12355000/pdf/fndds/ fndds3_doc.pdf. Accessed June 21, 2011.

40. Guenther PM, Reedy J, Krebs-Smith SM, Reeve BB, Basiotis PP: Development and evaluation of the healthy eating index-2005: technical report. Center for nutrition policy and promotion, U.S. Department of agriculture; 2007. http:// www.cnpp.usda.gov/HealthyEatinglndex.htm. Accessed June 21, 2011.

41. U.S. Department of Agriculture, Center for Nutrition Policy and Promotion: HE12005_NHANES0102.txt. http://www.cnpp.usda.gov/HealthyEatinglndex2005report.htm. Accessed June 21, 2011.

42. National Center for Health Statistics: The NHANES Anthropometry Procedures Manual. Revised; 2004. http://www.cdc.gov/nchs/data/nhanes/ nhanes_03_04/BM.pdf. Accessed June 21, 2011.

43. National Institutes of Health: National heart, lung, and blood institute. Clinical guidelines on the identification, evaluation, and treatment of overweight and obesity in adults. http://www.nhlbi.nih.gov/guidelines/obesity/ob_gdlns.pdf. Accessed January 26, 2012.

44. National Center for Health Statistics: NHANES 2001-2002 data release; May 2004. MEC examination. Blood pressure section of the Physician's examination. http://www.cdc.gov/nchs/data/nhanes/nhanes_01_02/bpx_b_doc.pdf. Accessed June 21, 2011.

45. National Health and Nutrition Examination Survey: 2003-2004 Data documentation, codebook, and frequencies. Total cholesterol and HDL. Last revised April; 2010. http://www.cdc.gov/nchs/nhanes/nhanes2003-2004/ 113_c.htm. Accessed June 21, 2011.

46. National Center for Health Statistics: NHANES documentation, codebook, and frequencies: survey years 2003-2004. MEC laboratory component: triglycerides and LDL-cholesterol; http://www.cdc.gov/nchs/data/nhanes/nhanes_03_04/ 113am_c.pdf. Accessed June 12, 2010.

47. National Center for Health Statistics: NHANES documentation, codebook, and frequencies: survey years 2003-2004. MEC laboratory component: plasma glucose, serum C-peptide, and insulin; http://www.cdc.gov/nchs/data/nhanes/ nhanes_03_04/110am_c.pdf. Accessed June 12, 2010.

48. National Cholesterol Education Program: National heart, lung, and blood institute. National institutes of health. Detection, evaluation, and treatment of high blood cholesterol in adults (adult treatment panel III); 2002. NIH Publication No. 02-5215.

49. Usual Dietary Intakes: SAS macros for analysis of a single dietary component. http://riskfactor.cancer.gov/diet/usualintakes/macros_single.html. Accessed June 12, 2010

50. Institute of Medicine. Food and Nutrition Board: Dietary reference intakes: applications in dietary assessment. Washington DC: National Academy Press; 2000.

51. National Center for Health Statistics: NHANES documentation, codebook, and frequencies: survey years 2003-2004. Physical activity. http://www.cdc.gov/ nchs/nhanes/nhanes2005-2006/PAQ_D.htm. Accessed August 29, 2011.

52. O'Neil CE, Nicklas TA, Rampersaud GC, Fulgoni VL 3rd: One hundred percent orange juice consumption is associated with better diet quality, improved nutrient adequacy, and no increased risk for overweight/ obesity in children. Nutr Res 2011, 31:673-682.

53. American Academy of Pediatrics: Committee on Nutrition. The use and misuse of fruit juice in pediatrics. Pediatrics 2001, 107:1210-1213.

54. US department of agriculture, 2005 dietary guidelines advisory committee report (2004) fruit and fruit juice analysis. http://www.health.gov/ dietaryguidelines/dga2005/report/HTML/G2_Analyses.htm\#fruitjuice. Accessed September 30, 2010.

55. Produce for better health. http://www.fruitsandveggiesmorematters.org. Accessed May 292010.

56. Centers for Disease Control and Prevention (CDC): State-specific trends in fruit and vegetable consumption among adults - United States, 2000-2009. MMWR Morb Mortal Wkly Rep 2010, 59:1125-1130.

57. Melgar-Quinonez HR, Kaiser LL: Relationship of child-feeding practices to overweight in low-income Mexican-American preschool-aged children. J Am Diet Assoc 2004, 104:1110-1119.

58. Alexy U, Sichert-Hellert W, Kersting M, Manz F, Schoch G: Fruit juice consumption and the prevalence of obesity and short stature in German preschool children: results of the DONALD (Dortmund Nutritional and Anthropometrical Longitudinally Designed Study). Pediat Gastroenterol Nutr 1999, 29:343-349.

59. Skinner JD, Carruth BR, Moran J 3rd, Houck K, Coletta F: Fruit juice intake is not related to children's growth. Pediatrics 1999, 103:58-64.

60. Skinner JD, Carruth BR: A longitudinal study of children's juice intake and growth: the juice controversy revisited. Am Diet Assoc 2001, 101:432-437.

61. O'Connor TM, Yang SJ, Nicklas TA: Beverage intake among preschool children and its effect on weight status. Pediatrics 2006, 118:e1010-8.

62. Newby PK, Peterson KE, Berkey CS, Leppert J, Willett WC, Colditz GA: Beverage consumption is not associated with changes in weight and body mass index among low-income preschool children in North Dakota. J Am Diet Assoc 2004, 104:1086-1094.

63. Bok SH, Lee SH, Park YB, Bae KH, Son KH, Jeong TS, et al: Plasma and hepatic cholesterol and hepatic activities of 3-hydroxy-3-methylglutarylCoA reductase and acyl CoA:cholesterol transferase are lower in rats fed citrus peel extract or a mixture of citrus bioflavonoids. J Nutr 1999, 129:1182-1185.

64. Jung UJ, Lee MK, Park YB, Kang MA, Choi MS: Effect of citrus flavonoids on lipid metabolism and glucose-regulating enzyme nRNA levels in type- 2 diabetic mice. Int J Biochem Cell Biol 2006, 38:1134-1145.

65. Kurowska EM, Hasegawa S, Manners GD: Regulation of apo B production in HepG2 cells by citrus limonoids. In Citrus limonoids: functional chemicals in agriculture and foods. Edited by Berhow EM, Hasegawa S, Manners GD. Washington, DC: American Chemical Society; 2000:175-84. ACS Symposium Series 758.

66. Tanasescu M, Ferris AM, Himmelgreen DA, Rodriguez N, Perez-Escamilla R: Biobehavioral factors are associated with obesity in Puerto Rican children. J Nutr 2000, 130:1734-1742.

67. Sanigorski AM, Bell AC, Swinburn BA: Association of key foods and beverages with obesity in Australian schoolchildren. Public Health Nutr 2007, 10:152-157.

68. Paynter NP, Yeh HC, Voutilainen S, Schmidt MI, Heiss G, Folsom AR, Brancati FL, Kao WH: Coffee and sweetened beverage consumption and the risk of type 2 diabetes mellitus: the atherosclerosis risk in communities study. Am J Epidemiol 2006, 164:1075-1084.

69. Odegaard AO, Koh WP, Arakawa K, Yu MC, Pereira MA: Soft drink and juice consumption and risk of physician-diagnosed incident type 2 diabetes: the Singapore Chinese Health Study. Am J Epidemiol 2010, 171:701-708.

doi:10.1186/1475-2891-11-107

Cite this article as: O'Neil et al:: $100 \%$ Orange juice consumption is associated with better diet quality, improved nutrient adequacy, decreased risk for obesity, and improved biomarkers of health in adults: National Health and Nutrition Examination Survey, 2003-2006. Nutrition Journal 2012 11:107.

\section{Submit your next manuscript to BioMed Central and take full advantage of:}

- Convenient online submission

- Thorough peer review

- No space constraints or color figure charges

- Immediate publication on acceptance

- Inclusion in PubMed, CAS, Scopus and Google Scholar

- Research which is freely available for redistribution 